\title{
Obituary
}

Dr A. S. Russell

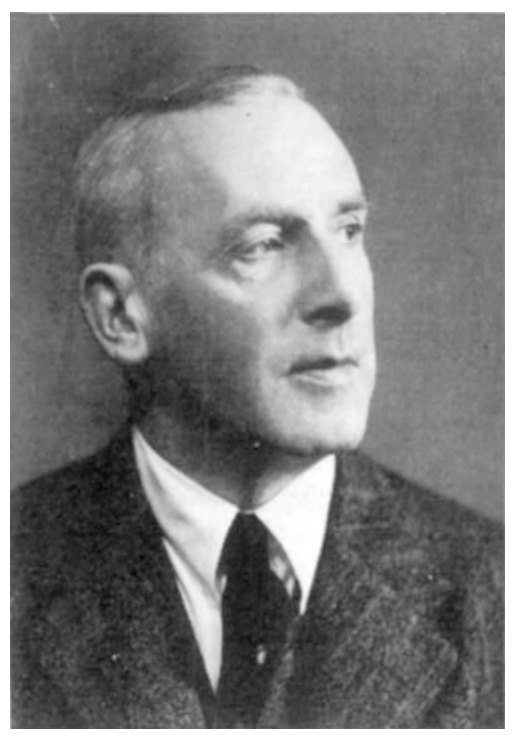

[Bassano and Vandyk

WITH the death in Oxford on March 15 of Dr A. S. Russell, MC, for many years tutor in chemistry at Christ Church, another link with the great days of Rutherford and the beginnings of nuclear physics has been broken. His important contributions to the chemistry of the radio elements which led to the concept of isotopes are now part of the history of the subject.

Alexander Smith Russell, the second son of Mr John Russell, of HM Inland Revenue Department, was born on May 31, 1888, at the small fishing town of Musselburgh near Edinburgh. $\mathrm{He}$ was educated in Glasgow at the High School and then went on to the University where he obtained his MA in Mathematics and Natural Philosophy, and his BSc in Chemistry. In 1908 he commenced his research in radioactivity at Glasgow University under the direction of Mr Soddy (later Professor and Nobel Laureate in Chemistry): this early work was on gamma radiation from the radio elements and at the time this constituted the most exhaustive study so far made. He then went to Berlin for a year where he gained research experience working with Professors Nernst and Marckwald on specific heat determinations and on the radioactive content of uranium minerals. On his return to England in 1911 he moved to the laboratory of Sir Ernest Rutherford (later Lord Rutherford) at Manchester where he resumed his research on the chemistry of the radio- active elements. It was during this period that he made some particularly significant contributions to the development of what came to be known as the "Displacement Law" and which led to the hypothesis and discovery of isotopes.

The Americans McCoy and Ross in 1907 , followed by many others, had discovered pairs of radio elements which were physically and chemically inseparable. Now the rare earth elements had already presented chemists with great difficulties in their separation but these radioactive "inseparable pairs" seemed to fall into a different class of difficulty. In 1910 Soddy who like the others had worked with purely chemical techniques suggested that the members of these pairs were "not mere analogies but chemical identities". A year later on rather slender evidence Soddy pointed out that alpha decay seemed to displace the chemical properties to the next group but one in the periodic classification. It was at this stage that Russell and Rossi reported that the emission spectrum of ionium was identical with that of thorium and concluded their paper with the significant statement " . . . but the possibility that thorium and ionium are identical in all physical and chemical properties and differ only in atomic weight and radioactive properties should not be lost sight of". At about this time Russell pointed out to Soddy the likelihood that radiogenic lead would have a different atomic weight from non-radiogenic lead, a fact subsequently established by Soddy and regarded by him as convincing proof of the isotope theory as applied to heavy elements. In January 1913 Russell published in Chemical News the first clear statement of the Displacement Law in which he showed that alpha decay displaced the chemical properties two places and beta decay one place in the periodic table. With this he was able to construct the radioactive decay chains and he forecast the existence between $U_{I}$ and UII of two beta emitters which were subsequently identified. Two weeks later Soddy spelled out the Displacement Law more correctly and acknowledged his debt to Russell for his earlier formulation. At the same time Fajans quite independently reached the same conclusions and published a complete statement of the law. Later that year Soddy coined the word "isotope" to indicate that these "inseparable pairs" lay in the same place in the periodic table.

In the following year war broke out and these exciting researches which are recorded in some 25 papers came to an abrupt end. Russell, still only 26 years old, joined the army and was commissioned in the Royal Garrison Artillery. He spent four years in the army, much of it in France engaged on sound ranging work at the front, and rose to the rank of captain. $\mathrm{He}$ was wounded twice, received several mentions in despatches and was awarded the Military Cross. On demobilization he became Senior Lecturer in Chemistry at Sheffield University and a year later was appointed Dr Lee's Reader in Chemistry at Christ Church where he remained until he retired in 1955.

During this post-war period he wrote two books and some 40 papers on his research, all marked by a beautiful succinctness and clarity which make them readily intelligible even to those unfamiliar with the field. Apart from his research in radiochemistry he was also interested in the occurrence of stable isotopes and he wrote several papers on empirical mathematical relationships which he concluded existed between the mass of a stable isotope and its atomic number. His major interest in these years, however, lay in metal chemistry, and he and his research students made an extensive study on the chemical stability and electrochemistry of inter-metallic compounds and amalgams.

His years as a college tutor gradually drew him into administration and in 1938 he was elected Censor of Christ Church, an office which he held throughout the Second World War and which brought him into touch with large numbers of undergraduates: his great interest in people and in their problems, and his wise guidance, earned their respect and support. When he relinquished office the members of the Junior Common Room presented him with a gold watch: such an unusual step showed with what affection he was regarded. His remarkable memory for facts, figures and personal histories was a valuable aid to his natural administrative ability. As a raconteur he was exceptional and his sense of humour, taste for the ridiculous and love of biographical detail made his stories riotously funny. Many had a strong scientific flavour and his acknowledgment of the genius of the Almighty for 
having invented the Moon as a device for keeping our beaches clean made even his clerical colleagues smile.

Dr Russell belonged to that group of Oxford chemistry tutors of the interwar years which was responsible for making the school internationally famous for the graduates which it produced. His hundreds of ex-pupils, all loyal and many distinguished, are as much a memorial to him as the contributions to knowledge which he made and which should be better known than perhaps they are.

\section{Professor Maria Goeppert-Mayer}

THE recent death of Maria GoeppertMayer is a cause for sorrow and regret to all who knew her and marks the end of a chapter in the history of nuclear physics.

Maria Goeppert was born in 1906 in Kattowice, then in Germany, and gained her $\mathrm{PhD}$ at the University of Göttingen, Germany, in 1930. In the same year she married Joseph Mayer and moved to Johns Hopkins University, Baltimore, with her husband. In 1933 she took out United States citizenship. She moved to Columbia University, New York, in 1939, becoming a senior physicist at Argonne National Laboratory and professor at the Enrico Fermi Institute of Nuclear Studies, Chicago, from 1946-1960. Since 1960 she and her husband have held chairs at $\mathrm{La}$ Jolla, California.

At Chicago she came under the influence of Enrico Fermi who suggested that she should see whether certain minor irregularities in nuclear systematics could be explained in terms of a model of the nucleus bearing certain similarities to the quantum mechanical model of the atom with its shells of tightly bound electrons. Thus was born the nuclear shell model which was to prove so fruitful for all later developments in nuclear theory. Previously it was thought that the short range and the extreme strength of nuclear forces would make a detailed description of the nucleus exceedingly difficult; indeed it was likened to a liquid drop in which the forces between the molecules have a similar character. It was not until the shell model had been well established empirically that it was realized that nuclear forces within the nucleus could not exert themselves as strongly as in empty space owing to the operation of the Pauli exclusion principle which, by limiting the states available to interacting particles to those not already occupied by other particles, effectively reduced their possibility for interaction. This is how it comes about that in spite of strong nuclear interactions the neutrons and protons within the nucleus behave in first approximation as if they are weakly interacting as do the electrons in the atom.

And so for the first time it became possible to develop detailed explanations of the spectra and other properties of nuclei. Although since those early days it has been realized that in addition to their near-independent particle motions nuclei also exhibit collective motions reminiscent of those originally imagined for a liquid drop nucleus, so that a nuclear spectrum resembles less that of an atom than a molecule (with its nearly independent electronic motions coupled to collective nuclear motions), the shell model remains the starting point for any meaningful considerations of nuclear structure.

It often happens in science that discoveries are made independently by more than one person or group. So it was with the nuclear shell model, for quite independently but simultaneously Hans Jensen and his colleagues in Heidelberg came to essentially the same conclusions. To add to the coincidence, Mayer and Jensen shared the same birthday. She and Jensen became close friends and colleagues and published a definitive account of their work in Elemeniary Theory of Nuclear Shell Structure in 1955. In 1963 her work was recognized by the award of the Nobel prize for physics, shared with Jensen and Wigner.

Mrs Mayer's early work was in statistical mechanics on which she worked jointly with her husband. Even after the discovery of the shell model, however, they collaborated closely. Indeed, the news of the shell model was brought to England by her husband in a lecture at the Clarendon Laboratory, Oxford. Their household was legendary for its hospitality, and their kindness and encouragement to young scientists knew no bounds even after the severe stroke which afflicted Mrs Mayer in her later years.

\section{Announcements}

\section{Miscellaneous}

Dr A. C. Allison, Clinical Research Centre, Harrow, will receive a Martin Luther King junior medical achievement award for his contributions to the study of sickle cell anaemia.

The 1972 Lenin Prizes for Science and Technology were awarded as follows: to Dr Zhores I. Alferov, of the "A. F. Ioffe" Institute of Physics and Technology of the Soviet Academy of Sciences, and to his team Vyacheslav M. Andreev, Dmitrii Z. Garbuzov, Vladimir I. Korol'kov, Vasilii I. Shveikin and Dmitrii N. Tret'yakov, for fundamental research on heterotransitions in semiconductors and the development of new devices based on this research; to Dr Vadim V. Afrosimov, Dr Vladimir M. Dukel'skii and Dr Nikolai V. Fedorenko of the "A. F. Ioffe" Institute of Physics and Technology of the Soviet Academy of Sciences, and to Dr Oleg B. Firsov and Vsevolod A. Belyaev of the "I. V. Kurchatov" Institute of Atomic Physics, for a cycle of works on "Elementary Processes and Inelastic Scatter in Atomic Collisions", published 1951-1970; to Academician Aleksei Z. Petrov of the Institute of Theoretical Physics of the Ukrainian Academy of Sciences, for a cycle of works on "Invariant-group Methods in the Theory of Gravitation"; to Academician Ivan M. Vinogradov, director of the "V. I. Steklov" Institute of Mathematics of the Soviet Academy of Sciences, for his monograph "Method of Trigonometric Sums in the Theory of Numbers", published in 1971; to Academician Ivan L. Knunyants of the Institute of Elemental Organic Compounds of the Soviet Academy of Sciences, for research on fluoro-organic compounds of the aliphatic series; to Academician Vladimir I. Smirnov, faculty head at the "M. V. Lomonosov" Moscow State University, Academician Georgii S. Dzotsenidze of the Geological Institute of the Georgian Academy of Sciences, and Dr Vasilii N. Kotlyar, faculty head at the Moscow "S. Ordzhonikidze" Institute of Geology and Prospecting, for various works on the ore-content of volcanic formations; to Academician Petr K. Anokhin, faculty head at the First Moscow "I. M. Sechenov" Institute, for his monograph "The Biology and Neurophysiology of the Conditioned Reflex", published in 1968; to Academician Aleksandr I. Baraev of the Lenin All-Union Academy of Agricultural Sciences, and his team, Aleksandr A. Zaitseva (All-Union Scientific Research Institute of Cereal Crops), Georgii G. Berestovskii (Pavlodar Soil Conservation and Erosion Research Station), Aleksandr A. Plishkin (All-Union Scientific Research Institute of Mechanization of Agriculture) and Ivan I. Khoroshilov (Soviet Ministry of Agriculture), for work on protection against wind erosion of soils in the North Caucausus and West Siberia; to Akop A. Sarkisov and his team, Evgenii I. Ozerskii (Central Asian Irrigation Control), Abdukarim K. Kasimov (Tadzhiktselinstroi), Tukhtamysh Baimirov (Golodnostepstroi), Dmitrii K. Tersitskii (director of the "Sredazgiprovodkhopok" Institute), Emmanuil M. Ben'yaminovich (of the same Institute), for research and implementation of irrigation methods for the virgin steppe; to Dr Boris S. Balakshin, faculty head at the Moscow Institute of Machine Tools and Instruments, and his team, Boris M. Bazrov, Sergei P. 